\title{
A dificuldade na aprendizagem da matemática
}

\section{The difficulty in learning mathematics regarding its language}

\author{
DOI: $10.54019 / \operatorname{sesv1n1-001}$
}

Recebimento dos originais: 06/01/2020

Aceitação para publicação: 31/01/2020

\author{
Emmanuel Zullo Godinho \\ Engenheiro Agrônomo/Pedagogo - Doutorando em Agronomia - Energia na \\ Agricultura pela Universidade Estadual Paulista (UNESP). \\ E-mail: emmanuel.godinho@unesp.br
}

\section{Emerson de Pietri}

Licenciado em Letras - Doutor em Linguística Aplicada ao Ensino/Aprendizagem de Língua Materna pelo Instituto de Estudos da Linguagem da Universidade Estadual de Campinas (UNICAMP).

E-mail: pietri@usp.br

\section{Helio Vagner Gasparotto}

Bacharel em Ciências Contábeis pela Instituto de Ensino Superior de Bauru (ITE). E-mail: helio.vagner@unesp.br

\section{RESUMO}

Para os alunos, só de ouvir "vamos ter aula de matemática" eles já se "fecham". Por isso, a comunicação entre o aluno, professor e o material didático deve ser "limpo" ou como é chamado "sem curvas", principalmente explicativo e de fácil entendimento. Diante desse contexto, o objetivo desse artigo é identificar como está configurado o estado do conhecimento da dificuldade do aluno perante a linguagem matemática existente. Para atender este objetivo, foi utilizada uma revisão bibliográfica sistemática, composta por três fases: Entrada, Processamento e Saída. Onde procurou responder a principal pergunta da pesquisa "como está configurado o estado do conhecimento sobre a linguagem na educação matemática"? Com base nos documentos analisados, pode-se concluir a linguagem matemática deve ser utilizada o mais simples possível e que seja bem direcionada para cada nível escolar, ou seja, uma aplicabilidade diferente para cada estudante. Sendo que dos 24 documentos analisados, 8 são capítulos de livros e o restante artigos científicos. Analisando o número de publicações sobre o tema entre 2015 a 2020 teve um aumento dobrado nos aceites dados científicos, onde foram publicados 16 documentos, já de 2009 a 2014 foram publicados apenas 8 artigos e principalmente tendo também 16 documentos publicados em nossa língua materna com 8 em inglês, o que demonstra que a análise de tal formato documental é relevante à temática aqui abordada. Reforçando a importância da linguagem e como a mensagem é transmitida para o destinatário na educação a nuvem de palavras apresentou palavras-chave com maiores citações Ensino Linguagem, Matemática, Educação, Comunicação Matemática e Jogos. 
Palavras-chave: Comunicação e Linguagem, Conhecimento Matemático, Linguagem Matemática, Revisão Bibliográfica Sistêmica.

\section{ABSTRACT}

For the students, just hearing "let's have math class" they already "close". Therefore, the communication between the student, the teacher and the teaching material must be "clean" or as it is called "without curves", mainly explanatory and easy to understand. Given this context, the objective of this article is to identify how the state of knowledge of the student's difficulty is configured in relation to the existing mathematical language. To meet this objective, a systematic bibliographic review was used, consisting of three phases: Input, Processing and Output. Where did you try to answer the main research question "how is the state of knowledge about language in mathematics education configured"? Based on the analyzed documents, it can be concluded that the mathematical language should be used as simple as possible and that it should be well-targeted for each school level, that is, a different applicability for each student. Of the 24 documents analyzed, 8 are book chapters and the rest are scientific articles. Analyzing the number of publications on the subject between 2015 and 2020 there was a doubled increase in accepted scientific data, where 16 documents were published, from 2009 to 2014 only 8 articles were published and mainly 16 documents were published in our mother tongue with 8 in English, which demonstrates that the analysis of such a document format is relevant to the topic addressed here. Reinforcing the importance of language and how the message is transmitted to the recipient in education, the word cloud presented keywords with the highest citations Teaching Language, Mathematics, Education, Mathematics Communication and Games.

Keywords: Communication and Language, Mathematical Knowledge, Mathematical Language, Systemic Literature Review.

\section{INTRODUÇÃO}

A linguagem apresenta grande importância para a humanidade por ser diferenciada entre o ser humano, em cada tempo e espaço, o processo de comunicação tem procurado adaptar-se de acordo com seu meio (OLIVEIRA, 2017). Com isso, diferentes linguagens surgiram para que pudesse conectar pessoas ao meio onde vivem, codificando palavras e frases, colocando-se diante de um movimento dinâmico de construção da própria linguagem (REZENDE et al., 2011).

A linguagem está atrelada a fatores essencialmente culturais:

As esferas da atividade humana, por mais variadas que sejam, estão sempre relacionadas com a utilização da língua, ou seja, toda atividade humana passa pelo caminho da linguagem, em que são interrelacionadas através das intenções, do sentido atribuído, do momento vivido pelo sujeito, possibilitando uma atitude responsiva diante das palavras e seus escritos (BAKHTIN, 1997, p. 279). 
(BAKHTIN, 1997) salienta que o a comunicação deve ser estruturada, pois:

\begin{abstract}
Aprender a falar é aprender a estruturar enunciados (porque falamos por enunciados e não por orações isoladas e, menos ainda, é óbvio, por palavras isoladas). Os gêneros do discurso organizam nossa fala da mesma maneira que a organizam as formas gramaticais (sintáticas). Aprendemos a moldar nossa fala às formas do gênero e, ao ouvir a fala do outro, sabemos de imediato, bem nas primeiras palavras, pressentirIhe o gênero, adivinhar-Ihe o volume (a extensão aproximada do todo discursivo), a dada estrutura composicional, prover-lhes o fim, ou seja, desde o início, somos sensíveis ao todo discursivo que, em seguida, no processo da fala, evidenciará suas diferenciações. Se não existissem os gêneros do discurso e se não os dominássemos, se tivéssemos de criálos pela primeira vez no processo da fala, se tivéssemos de construir cada um de nossos enunciados, a comunicação verbal seria quase impossível (BAKHTIN, 1997, p. 302).
\end{abstract}

Da mesma forma, a comunicação entre pessoas deve ter um fundamento de responsividade, (ALVARENGA; MALHADO; LINS, 2014), apresentam que responsividade não possui um conceito direto, mas está relacionado com uma fácil interação entre pessoas, quando as mesmas se comunicam sem ruídos nas mensagens trocadas. Dessa maneira o sujeito se torna mais acessível e "aberto" para uma discussão direcionamento e por fim aonde ele pode se posicionar perante a fala dos outros membros (TIRADO CARVAJAL; GUALDRÓN PINTO; ÁVILA ZÁRATE, 2019). Por isso, é importante em uma comunicação seja aberta para ambos os lados, ou seja, tanto para o emissor quanto para o receptor. Entretanto, ainda nos dias atuais a comunicação na matemática apresenta uma grande dificuldade entre o emissor e o receptor, pois em algum momento ou 0 emissor ou o receptor tem dificuldades no entendimento de como a mensagem é transmitida:

\footnotetext{
É de acordo com nosso domínio dos gêneros que usamos com desembaraço, que descobrimos mais depressa e melhor nossa individualidade neles (quando isso nos é possível e útil), que refletimos, com maior agilidade, a situação irreproduzível da comunicação verbal, que realizamos, com o máximo de perfeição, o intuito discursivo que livremente concebemos. Portanto, o locutor recebe, além das formas prescritivas da língua comum (os componentes e as estruturas gramaticais), as formas não menos prescritivas do enunciado, ou seja, os gêneros do discurso, que são tão indispensáveis quanto as formas da língua para um entendimento recíproco entre locutores (BAKHTIN, 1997, p. 304).
}

Por ser uma ciência exata, a matemática possui grande importância na 
origem histórica na busca rigorosa de fundamentos (DIONIZIO et al., 2018). Considerada uma ciência que contribui para a criação de um mundo próprio e isolado, sendo que somente os matemáticos e os estudiosos desta língua especifica poderiam ter este entendimento (KLUSENER, 2007).

Além disso, a matemática forneceu diversos modelos e métodos de pensamentos, que ao mesmo tempo se torna eficaz para a sociedade moderna em diversos gêneros (MONTOITO, 2019). (KLUSENER, 2007) coloca que a linguagem matemática tem um papel fundamental e importante em nosso meio de comunicação, porque através dela que a sociedade entende e compreende o meio social e o mundo ao nosso redor.

Entretanto, nas escolas o ensino de matemática é considerado por muitos pensadores um modelo de conceito "fracassado", sendo que esta mudança só poderá ser alterada com uma mudança pedagógica geral (MOREIRA; MOREIRA, 2018).

Os estudantes não conseguem expor as dificuldades e a grande maioria não gosta dessa disciplina, ocorrendo assim um aumento na evasão escolar, com o principal argumento entre os alunos sobre o não entendimento dos conteúdos de exatas, principalmente matemática. Tendo em vista, que a linguagem matemática é especifica e quando não transmitida perfeitamente, a mensagem pode não chegar para o receptor como o emissor deseja. Pois, os alunos podem não distinguir como operacionalizar os cálculos:

Conhecer e distinguir os números e talvez as quatro operações aritméticas, é primordial para que o aluno seja capaz de analisar criticamente ou até mesmo tirar conclusões a partir de informações numéricas (KLUSENER, 2007, p. 181).

Além de disso, a fundamentação teórica da matemática relacionando com a interpretação de textos é fundamental para que o aluno possa desenvolver e aplicar as metodologias no ensino da matemática:

[...] é fundamental compreender o sentido do fenômeno da alfabetização matemática. Ser alfabetizado em matemática é entender o que se lê e escreve, o que se entende a respeito das primeiras noções de aritmética, geometria e lógica, sem perder a dimensão social e cultural desse processo: é buscar o significado do ato de ler e de escrever, presentes na prática cotidiana. Para ser alfabetizado, basta simplesmente saber ler, escrever e contar [...] (KLUSENER, 2007, p. 181-182). 
Entende-se que a linguagem que se usa nos livros matemáticos estão além da capacidade de compreensão dos alunos, cabendo neste momento a participação do professore como transformar estas linguagem "obscuras" em sinais "abertos e de fácil entendimento" (DE SOUZA CHIARI; DE CARVALHO BORBA; SOUTO, 2019).

De acordo com (DE ANDRADE et al., 2020), o professor, é considerado o principal responsável pela organização do discurso da aula, situando "livros e alunos", que venham a favorecer a ligação matemática a realidade do estudante.

Diante desse contexto, o objetivo desse artigo é identificar como está configurado o estado do conhecimento a respeito da dificuldade do aluno perante a linguagem matemática existente.

\section{MATERIAIS E MÉTODOS}

Objetivando a pergunta da pesquisa "Como está configurado o estado do conhecimento sobre a linguagem na educação matemática"? Que, segundo (SCHNEIDER et al., 2020) é, um enunciado interrogativo que questiona sobre a possível relação direta das variáveis que estão envolvidos na linguagem da educação matemática, onde foi aplicado uma revisão bibliográfica como sendo o verdadeiro "fator produtivo" da pesquisa.

A metodologia de pesquisa adotada para este artigo, que segundo (BURIGO; PORTO, 2019), foi a de prospecção de documentos em bases científicas. Esta metodologia, apresenta uma técnica que o autor deve mapear e separar os dados dentro dos detalhes apresentados para que possa validar a sua resposta final a pergunta apresentada (CONFORTO; AMARAL; SILVA, 2011). Por isso, adotou-se a Revisão Bibliográfica Sistemática (RBS) como base metodológica para a realização do presente estudo.

A Revisão Bibliográfica Sistemática é um método que autores podem se conectar com resultados de pesquisa em uma determinada área específica, onde é adotado uma metodologia que possa sintetizar o conhecimento existente sobre o tema (CONFORTO; AMARAL; SILVA, 2011).

A RBS tem uma particularidade que autores de diversas áreas podem reproduzir, pois a mesma norteia o desenvolvimento de projetos e as buscas em determinadas bases de consulta científica, para que isso ocorra o autor necessita 
definir qual sua estratégia de busca com os critérios de inclusão ou exclusão e por fim fazer uma leitura minuciosa de cada item selecionado (BRERETON et al., 2007).

Para que o objetivo fosse concretizado, foi realizado uma revisão bibliográfica sistemática, adotando-se o método desenvolvido por (AQUINO et al., 2020), que é composto por três fases: Entrada, Processamento e Saída.

Inicia-se com a fase chamada de entrada, definindo os critérios de inclusão e exclusão em função do objetivo proposto, sendo criado as Strings de busca. A segunda fase é chamada de processamento, sendo uma das fases mais importantes, onde seleciona os documentos por meio de leitura, análise e a seleção final com os documentos que se destacaram em relação a fase 1 e 2 . A última fase é conhecida como saída que é onde os documentos são arquivados para que posterior possa elaborar a síntese dos resultados obtidos.

\subsection{ENTRADA}

Foi escolhida como base de dados de acordo com sua relevância na área de estudo, sendo utilizada a SciELO - Scientific Electronic Library Online.

Inicialmente, foi realizado no site de busca utilizando as principais palavraschave tanto na língua inglesa como no português (matemática, mathematic, linguagem e language). Os resultados obtidos tiveram valores expressivos (altos), para matemática 4.092 documentos, mathematic 382 documentos, linguagem 5.551 documentos e language 16.709 documentos, totalizando 26.734 documentos, para uma busca e leitura mais aprofundada para o trabalho este valor é bem alto, por isso, foi utilizado uma junção entre as duas palavras-chave linguagem e matemática.

Com isso, foi realizado uma nova busca com a String ("linguagem" AND "matemática"), como pode-se observar no Quadro 1, totalizando 119 arquivos (pesquisa realizada no dia 07 de maio de 2021).

Quadro 1 - Definição da String de busca.

\begin{tabular}{|l|l|}
\hline String de busca & SciELO - Scientific Electronic Library Online \\
\hline ("linguagem" AND “matemática") & 119 \\
\hline
\end{tabular}

Fonte: Autores.

Este Quadro 1, exibe a String que foi elencado para a busca e a 
conformação da frase de filtro com o seu devido conectivo para que o software possa varrer a rede e os respectivos bancos de dados da base científica, apresentando os resultados obtidos do filtro.

Optou-se por não delimitar a pesquisa a artigos, pois acredita-se que possam existir outros tipos de documentos relevantes para a problemática apresentada.

Os critérios iniciais para inclusão de documentos estão apresentados no Quadro 2.

Quadro 2 - Filtros iniciais aplicados na base de dados.

\begin{tabular}{|l|l|l|}
\hline Base de dados & \multicolumn{1}{|l|}{ SciELO } & \multicolumn{1}{l|}{$\begin{array}{l}\text { Total de documentos } \\
119\end{array}$} \\
\hline Data da busca e exportação & 119 & 119 \\
\hline Resultado 1 (periódicos totais) & \multicolumn{2}{l|}{} \\
\hline Filtro 1 - Lapso de tempo (2010 a 2020) & 32 & 87 \\
\hline Rejeitados por estarem fora do lapso de tempo & \multicolumn{2}{l|}{} \\
\hline Filtro 2 - Idioma (Inglês e Português) & 77 \\
\hline Rejeitados por estarem fora dos idiomas analisados & 10 & 50 \\
\hline Filtro 3 - Disponível em texto integral (.pdf) & 27 & 50 \\
\hline Rejeitados por não terem o arquivo .pdf &
\end{tabular}

Fonte: Autores.

Como pode-se observar no Quadro 2, os critérios iniciais para inclusão de documentos foram: delimitação do lapso temporal (2010 a 2020 - dez anos) com o intuito de observar a evolução da temática abordada, e idiomas de interesse (inglês e português) - por conveniência), totalizando 50 documentos, como apresentado no Quadro 2.

Além disso, no filtro 3, foi observado rejeição por não terem o arquivo .pdf, isto quer dizer que no momento os artigos foram baixados via Mendeley $\AA_{\text {, }}$ diretamente dos sites de busca, o mesmo não acompanhou o arquivo inteiro, somente o resumo, como o intuito era ter todos os artigos para que pudesse ler e estuda-lo para que pudesse melhor se encaixar no trabalho.

\subsection{PROCESSAMENTO}

Com os documentos previamente selecionados, e com a base nos critérios da fase inicial (Entrada), iniciou-se a etapa de processamento, na qual foram exportados 50 documentos em arquivos no formato do Software Mendeley®. 
Na sequência, já com o uso do Software Mendeley®, foram identificados os documentos duplicados automaticamente (Filtro 4), totalizando os mesmos 50 documentos. A partir de então, foram realizadas análises textuais iniciais dos documentos, sendo avaliados os títulos, resumos e palavras-chaves para verificação de conformidade com os termos da pesquisa, onde foram aceitos todos os documentos que traziam termos relacionados à linguagem com matemática, como pode-se observar no Quadro 3, que apresenta os filtros 4, 5 e 6 , bem como seus resultados.

Quadro 3 - Filtros na etapa de seleção.

\begin{tabular}{|c|c|c|}
\hline \multicolumn{2}{|c|}{$\begin{array}{ll}\text { Base de dados } & \text { SciELO } \\
\end{array}$} & \multirow{2}{*}{$\begin{array}{l}\text { Total de documentos } \\
50\end{array}$} \\
\hline Base de dados & 07/05/2021 & \\
\hline $\begin{array}{l}\text { Filtro } 4 \text { - Arquivos duplicados identificados pelo } \\
\text { Mendeley }\end{array}$ & 0 & 50 \\
\hline \multicolumn{3}{|c|}{ Filtro 5 - Rejeitados na análise de texto (resumo, palavras-chave) } \\
\hline $\begin{array}{l}\text { Rejeitados por não estarem em conformidade com a } \\
\text { pesquisa }\end{array}$ & 26 & 24 \\
\hline \multicolumn{3}{|l|}{ Filtro 6 - Rejeitados na análise detalhada } \\
\hline $\begin{array}{l}\text { Rejeitados por não estarem em conformidade com a } \\
\text { pesquisa }\end{array}$ & 0 & 24 \\
\hline
\end{tabular}

Fonte: Autores.

O Quadro 3, apresenta os resultados obtidos da fase de seleção de documentos nas respectivas bases prospectadas, com a aplicação de cada um dos filtros 4, 5 e 6, pode-se verificar que a maior redução de documentos foi no âmbito da análise de rejeição quanto a não conformidade com a pesquisa (Filtro 5). Este filtro buscou selecionar os documentos que possuíam as palavras linguagem e matemática. Resultando assim, um total de 24 documentos para análise final. Estes documentos passaram para a etapa de leitura integral e análise detalhada, para posterior tabulação e apresentação dos resultados.

\subsection{SAÍDA}

Foram baixados, então, os 24 documentos como listado no Quadro 4, sendo que, todos foram lidos na íntegra e tabulados de forma a apresentar os resultados obtidos. 
Quadro 4 - Documentos analisados na íntegra para revisão bibliográfica sistemática.

\begin{tabular}{|c|c|c|c|}
\hline N. & Autor & Título & Aplicação \\
\hline 1 & $\begin{array}{l}\text { (CARMO; CARVALHO, } \\
\text { 2009) }\end{array}$ & $\begin{array}{l}\text { Construindora a } \\
\text { linguagem gráfica em } \\
\text { umaraula } \\
\text { experimental de física }\end{array}$ & $\begin{array}{l}\text { Aplicação do professor em utilizar uma } \\
\text { linguagem mais acessível para os } \\
\text { fenômenos da física }\end{array}$ \\
\hline 2 & (LORENSATTI, 2009) & $\begin{array}{lr}\text { Linguagem } & \\
\text { matemática } & \text { e Língua } \\
\text { portuguesa: } & \text { diálogo } \\
\text { necessário } & \text { na } \\
\text { resolução } & \text { de } \\
\text { problemas } & \\
\text { matemáticos } & \end{array}$ & $\begin{array}{l}\text { Aplicação de uma estratégia para } \\
\text { minimizar as dificuldades no } \\
\text { aprendizado dos alunos quanto as } \\
\text { linguagens matemáticas }\end{array}$ \\
\hline 3 & (REZENDE et al., 2011) & $\begin{array}{lr}\text { Qualidade } & \text { da } \\
\text { Educação } & \text { Científica } \\
\text { na voz } & \text { dos } \\
\text { professores } & \end{array}$ & $\begin{array}{l}\text { O uso bem definido dos sentidos das } \\
\text { palavras para a explicação dos } \\
\text { professores aos alunos }\end{array}$ \\
\hline 4 & $\begin{array}{l}\text { (PAVANELLO; LOPES; } \\
\text { ARAUJO, 2011) }\end{array}$ & $\begin{array}{l}\text { Leitura e interpretação } \\
\text { de enunciados de } \\
\text { problemas escolares } \\
\text { de matemática por } \\
\text { alunos do ensino } \\
\text { fundamental regular e } \\
\text { educação de jovens e } \\
\text { adultos (EJA) }\end{array}$ & $\begin{array}{l}\text { O uso da comunicação dos exercícios } \\
\text { para o bom entendimento dos alunos } \\
\text { quanto as devidas respostas }\end{array}$ \\
\hline 5 & $\begin{array}{l}\text { (BOCASANTA; } \\
\text { KNIJNIK, 2012) }\end{array}$ & $\begin{array}{l}\text { Escola e sociedade de } \\
\text { consumidores: um } \\
\text { estudo com crianças } \\
\text { "catadoras" }\end{array}$ & $\begin{array}{l}\text { Observações dos alunos com relação } \\
\text { ao trabalho manual com as estruturas } \\
\text { matemáticas }\end{array}$ \\
\hline 6 & $\begin{array}{l}\text { (LUVISON; GRANDO, } \\
\text { 2012) }\end{array}$ & $\begin{array}{l}\text { Gêneros textual e a } \\
\text { matemática: Uma } \\
\text { articulação possível } \\
\text { no contexto da sala de } \\
\text { aula }\end{array}$ & $\begin{array}{l}\text { Investigação dos conhecimentos } \\
\text { matemáticos em um contexto de } \\
\text { leitura e produção escrita em } \\
\text { situações de jogos, para resolução de } \\
\text { problemas }\end{array}$ \\
\hline 7 & (DUARTE et al., 2013) & $\begin{array}{l}\text { A linguagem no } \\
\text { ensino de matemática }\end{array}$ & $\begin{array}{l}\text { Reforçar aos educadores que a } \\
\text { comunicação e a linguagem na } \\
\text { constituição do conhecimento } \\
\text { matemático desperta maior interesse } \\
\text { pelo conteúdo matemático }\end{array}$ \\
\hline 8 & $\begin{array}{l}\text { (KNIJNIK; JUNGES, } \\
2014)\end{array}$ & $\begin{array}{l}\text { A Relação Família- } \\
\text { Escola e a Prática do } \\
\text { "Dever de Casa" de } \\
\text { Matemática: um } \\
\text { estudo sobre seus } \\
\text { tensionamentos }\end{array}$ & $\begin{array}{l}\text { A apresentação de como utilizar a } \\
\text { linguagem do "dever de casa" para a } \\
\text { disciplina de matemática objetivando a } \\
\text { relação na família }\end{array}$ \\
\hline 9 & (DIAS; DIAS, 2015) & $\begin{array}{lr}\text { Escrevendo o "Livro } \\
\text { da Natureza" na } \\
\text { linguagem } & \text { da } \\
\text { matemática: } & \text { A lei } \\
\text { Ampère } & \end{array}$ & $\begin{array}{l}\text { Reescrito a "lei de Ampere" em uma } \\
\text { forma mais suave para melhor } \\
\text { entendimento dos alunos no uso da } \\
\text { matemática }\end{array}$ \\
\hline 10 & $\begin{array}{l}\text { (DOURADO; } \\
\text { CARVALHO; LEMOS, } \\
\text { 2015) }\end{array}$ & $\begin{array}{l}\text { Development of } \\
\text { communication of } \\
\text { children aged between } \\
\text { one and three years } \\
\text { old and their } \\
\text { relationship with the } \\
\text { family and school } \\
\text { environments }\end{array}$ & $\begin{array}{l}\text { O uso da linguagem apropriada, } \\
\text { atraindo as crianças de } 1 \text { a } 3 \text { anos } \\
\text { juntamente com seus familiares nos } \\
\text { conteúdos educacionais }\end{array}$ \\
\hline 11 & (ALMEIDA, 2015) & Matemática concreta & Conhecer a escrita desde \\
\hline
\end{tabular}




\begin{tabular}{|c|c|c|c|}
\hline & & & $\begin{array}{l}\text { primórdios a aplicação de conceitos } \\
\text { matemáticos atuais }\end{array}$ \\
\hline 12 & $\begin{array}{l}(\text { SILVA; } \\
\text { BORBA, 2016) }\end{array}$ & $\begin{array}{lr}\text { Construção } & \text { da } \\
\text { reflexão na } & \text { escrita } \\
\text { acadêmica } & \text { por } \\
\text { professores } & \text { em } \\
\text { formacão inicial } & \end{array}$ & $\begin{array}{l}\text { O uso de orações desenvolvidas pelos } \\
\text { educadores tende a melhorar a } \\
\text { interpretação dos alunos na leitura e } \\
\text { entendimento final }\end{array}$ \\
\hline 13 & (VALLILO, 2016) & $\begin{array}{l}\text { O estudo da } \\
\text { Linguagem } \\
\text { Matemática na sala de } \\
\text { aula: uma abordagem } \\
\text { através da Resolução } \\
\text { de Problemas }\end{array}$ & $\begin{array}{l}\text { Artigo o qual apresenta resultados } \\
\text { satisfatórios sobrea metodologia de } \\
\text { Ensino-Aprendizagem no âmbito de } \\
\text { avaliações da matemática, utilizando a } \\
\text { metodologia de Thomas Romberg }\end{array}$ \\
\hline 14 & (AMARAL et al., 2017) & $\begin{array}{l}\text { Competências de } \\
\text { matemática e de } \\
\text { literacia emergente: } \\
\text { Estudo correlacional }\end{array}$ & $\begin{array}{l}\text { Apresentação de resultados quanto as } \\
\text { aplicações de dados orais e } \\
\text { fenológicos para crianças em estágio } \\
\text { pré-educacional }\end{array}$ \\
\hline 15 & $\begin{array}{l}\text { (FELIX; CARRAZEDO; } \\
\text { POSSAN, 2017) }\end{array}$ & $\begin{array}{l}\text { Parametric analysis of } \\
\text { carbonation process in } \\
\text { reinforced } \quad \text { concrete } \\
\text { structures } \\
\text { Artificial } \quad \text { Neural } \\
\text { Networks }\end{array}$ & $\begin{array}{l}\text { Uso de uma lógica na linguagem de } \\
\text { estudo para a construção em função } \\
\text { da aplicação de concreto }\end{array}$ \\
\hline 16 & (KRIPKA et al., 2017) & $\begin{array}{l}\text { Educação em ciências } \\
\text { e matemática: a } \\
\text { função da linguagem } \\
\text { no contexto da sala de } \\
\text { aula }\end{array}$ & $\begin{array}{l}\text { Aplicação de uma linguagem simples } \\
\text { e direcionada nas disciplinas de } \\
\text { matemática e ciências }\end{array}$ \\
\hline 17 & (RODRIGUES, 2017) & $\begin{array}{l}\text { Eficácia docente no } \\
\text { ensino da matemática }\end{array}$ & $\begin{array}{l}\text { O uso de boas práticas na linguagem } \\
\text { informal e não clássica para o ensino } \\
\text { da matemática }\end{array}$ \\
\hline 18 & (OLIVEIRA, 2017) & $\begin{array}{l}\text { Palavra de Ordem em } \\
\text { Aula de Matemática: } 0 \\
\text { erro e a besteira }\end{array}$ & $\begin{array}{l}\text { O reinventar do educador perante os } \\
\text { alunos demostraram que é eficiente na } \\
\text { condução da aula }\end{array}$ \\
\hline 19 & $\begin{array}{l}(\text { JELINEK; } \\
\text { 2018) }\end{array}$ & $\begin{array}{l}\text { The Production of the } \\
\text { Subject with High } \\
\text { Abilities in } \\
\text { Mathematics and } \\
\text { School Inclusion in } \\
\text { Contemporary } \\
\text { Education }\end{array}$ & $\begin{array}{l}\text { Aplicação de novos modelos de } \\
\text { pensamentos quanto aos alunos de } \\
\text { altas habilidades na questão do poder } \\
\text { dos jogos }\end{array}$ \\
\hline 20 & $\begin{array}{l}\text { (LAMÔNICA et al., } \\
\text { 2018) }\end{array}$ & $\begin{array}{l}\text { Klinefelter syndrome: } \\
\text { a speech-language } \\
\text { and } \\
\text { neuropsychological } \\
\text { assessment }\end{array}$ & $\begin{array}{l}\text { Uso da linguagem mais acessível } \\
\text { como ponto de partida para o ensino e } \\
\text { aprendizagem educacional }\end{array}$ \\
\hline 21 & $\begin{array}{l}\text { (SEPÚLVEDA; } \\
\text { CALDERÓN; } \\
\text { ESPINOZA, 2019) }\end{array}$ & $\begin{array}{l}\text { Characterization of } \\
\text { pedagogical practice } \\
\text { of high school } \\
\text { teachers participating } \\
\text { on the program of } \\
\text { assistance and } \\
\text { effective access to } \\
\text { higher education }\end{array}$ & $\begin{array}{l}\text { Uso do Acompanhamento e Acesso } \\
\text { Eficaz ao Ensino Superior (PACE) } \\
\text { para estudantes em vulnerabilidade } \\
\text { familiar na educação do ensino } \\
\text { superior }\end{array}$ \\
\hline 22 & $\begin{array}{l}\text { (BARTHOLO et al., } \\
\text { 2020) }\end{array}$ & $\begin{array}{l}\text { The use of cognitive } \\
\text { instruments for } \\
\text { research in } \\
\text { early childhood } \\
\text { education: constraints }\end{array}$ & $\begin{array}{l}\text { A utilização do instrumento } \\
\text { Perfomance Indicator for Primary } \\
\text { Schools (iPIPS) com crianças entre } 4 \\
\text { e } 7 \text { anos, mapeando o } \\
\text { desenvolvimento destas crianças em }\end{array}$ \\
\hline
\end{tabular}




\begin{tabular}{|c|c|c|}
\hline & & $\begin{array}{ll}\begin{array}{l}\text { and possibilities in the sistema de vulnerabilidade para } 0 \\
\text { Brazilian context }\end{array} & \text { futuro na educação }\end{array}$ \\
\hline 23 & $\begin{array}{l}\text { (PELOSI; FERREIRA; } \\
\text { NASCIMENTO, 2020) }\end{array}$ & $\begin{array}{l}\text { Occupational therapy } \\
\text { activities developed Aplicação de terapia ocupacional em } \\
\text { with children and pre- crianças com síndrome de Down para } \\
\text { teens with down melhorar a performance educacional } \\
\text { syndrome }\end{array}$ \\
\hline 24 & $\begin{array}{l}\text { (MADALENA; } \\
\text { CORREA; SPINILLO, } \\
\text { 2020) }\end{array}$ & $\begin{array}{l}\text { Mathematical } \\
\text { knowledge and Investigação da habilidade de } \\
\text { language in deaf recitação, constitutiva do conceito de } \\
\text { students: }{ }^{2} \text { The número, e sua relação com } \\
\text { relationship between habilidades linguísticas em Língua } \\
\text { the recitation of a Brasileira de Sinais em escolas de } \\
\text { numerical sequence surdos } \\
\text { and Brazilian sign surdos } \\
\text { language proficiency }\end{array}$ \\
\hline
\end{tabular}

Fonte: Autores.

O Quadro 4 exibe a lista de todos os 24 artigos selecionados para a pesquisa indicando sua contribuição para o meio acadêmico.

\section{RESULTADOS E DISCUSSÃO}

Com base nos critérios adotados nesta revisão sistemática, foi possível identificar um avanço nas produções científicas relacionada a aplicação da linguagem na matemática, reforçando assim sua importância acadêmica.

Onde foi identificado nos trabalhos analisados, a participação de professores, acadêmicos, pensadores renomados na área da linguagem correlacionando a dificuldade no entendimento do aluno quanto a matemática.

Nos documentos utilizados como fonte para a pesquisa, tiveram analises de múltiplas técnicas desde observação, entrevistas, questionários, ou seja, dados qualitativos e, até dados quantitativos com aplicação de testes estatísticos.

As questões respondidas nestes documentos analisados, em sua maioria respondiam a qual a dificuldade do entendimento do aluno perante a linguagem matemática ou as ciências exatas. Outros documentos traziam resultados de progressos no desenvolvimento de novas técnicas utilizadas de professores para com seus alunos no âmbito do conhecimento da linguagem matemática.

Diante destes dados coletados, os artigos foram organizados em diversas categorias, como: ensino-aprendizagem; atuação docente; linguagem matemática e formação de professores.

Observando as publicações nos últimos 10 anos (2010 a 2020), ocorreram um aumento na quantidade de estudos qualificados no tema estudado, sobre a 
temática da dificuldade no aprendizado do aluno quanto ao conhecimento das ciências exatas, principalmente na matemática. A Figura 1, apresenta o número de publicações por ano obtidas na pesquisa.

Figura 1 - Publicações por ano.

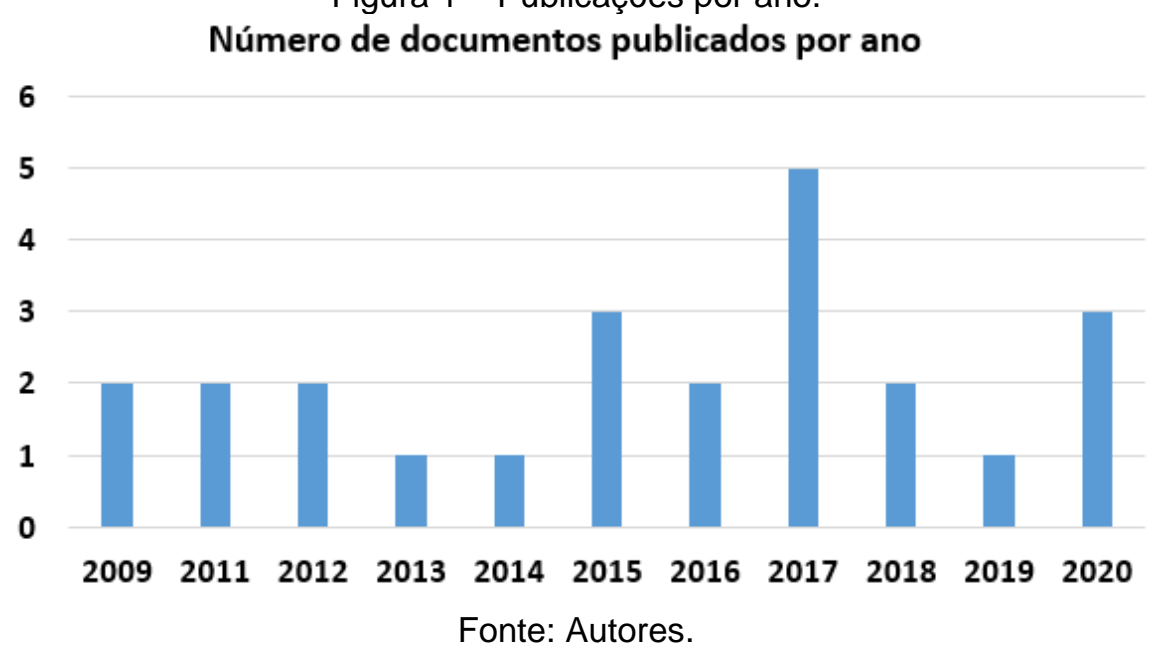

A Figura 1, apresenta o número de publicações por ano, dos 24 documentos selecionados, 16 foram publicados nos últimos 5 anos, ou seja, o dobro em relação aos anos anteriores. Observa-se um crescimento nos últimos 3 anos (2018 a 2020), um crescimento na publicação de artigos de aproximadamente $50 \%$, o que reforça a importância dos estudos da linguagem nos estudos das ciências exatas.

A Figura 2, corresponde aos termos encontrados nas palavras-chave dos artigos em português. 
Figura 2 - Nuvem de palavras.

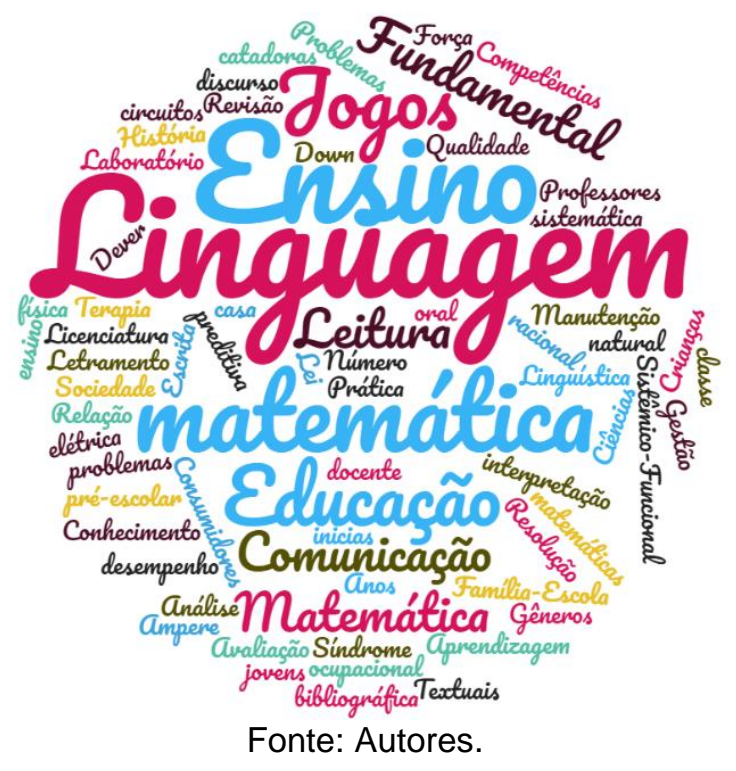

Conforme a nuvem de palavras (Figura 2), apresenta as palavras-chave que mais se destacaram nos artigos selecionados para o documento criado, tendo como principal a Linguagem, na sequência com Educação matemática e Comunicação. O termo linguagem apareceu cinco vezes mais em relação aos demais termos.

A Figura 3 corresponde a nuvem de palavras gerada a partir das palavraschave dos artigos selecionados na língua inglesa, com destaque a palavra: Educational.

Figura 3 - Nuvem de palavras.

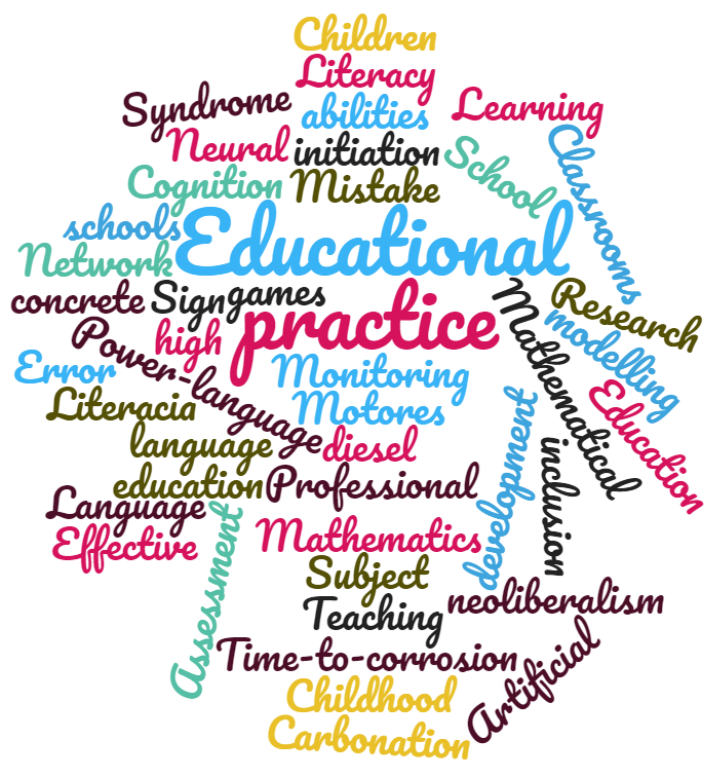

Fonte: Autores. 
A nuvens de palavras (NP) são imagens usualmente apresentadas como ilustração à leitura superficial do senso comum (VASCONCELLOS-SILVA; SAWADA, 2018). O tamanho de cada palavra indica sua frequência, admitida como proxy da relevância de determinada temática (PRAIS; ROSA, 2017) na totalidade de hipertextos.

Por mais que o tema de busca dos artigos fossem as mesmas Strings, as palavras-chave encontradas na língua portuguesa em relação a língua inglesa são diferentes para analise, na língua portuguesa o grande foco é a educação matemática juntamente com a linguagem, o que corrobora com a pergunta na criação deste artigo.

\section{CONCLUSÃO}

Com base nos documentos analisados, pode-se concluir a linguagem matemática deve ser utilizada o mais simples possível e que seja bem direcionada para cada nível escolar, cultura sócio educacional, ou seja, uma aplicabilidade diferente para cada sujeito -aluno. Mesmo sabendo que existe questões de conhecimento da língua portuguesa.

Dos 24 documentos analisados nesta pesquisa, cinco são capítulos de livros, além de ter o número dobrado em publicações de 2015 a 2020, onde foi publicado 16 documentos contra 8 de 2009 a 2014 e principalmente tendo também 16 documentos publicados em nossa língua materna com 8 em inglês, o que demonstra que a análise de tal formato documental é relevante à temática aqui abordada.

Reforçando a importância da linguagem e como a mensagem é transmitida para o ouvinte na educação a nuvem de palavras apresentou palavras-chave com maiores citações Ensino Linguagem, Matemática, Educação, Comunicação Matemática e Jogos.

Para trabalhos futuros, recomenda-se a análise mais aprofundada sobre a dificuldade da linguagem matemática nas séries específicas do ensino fundamental I, II e ensino média. 


\section{REFERÊNCIAS}

ALMEIDA, M. W. B. Matemática concreta. Sociologia \& Antropologia, v. 5, n. 3, p. 725-744, dez. 2015.

ALVARENGA, P.; MALHADO, S. DE C. B.; LINS, T. C. DE S. O impacto da responsividade materna aos oito meses da criança sobre as práticas de socialização maternas aos 18 meses. Estudos de Psicologia (Natal), v. 19, n. 4, p. 305-314, 2014.

AMARAL, J. et al. Competências de matemática e de literacia emergente: Estudo correlacional. Revista Portuguesa de Educação, v. 30, n. 1, p. 85, 19 maio 2017.

AQUINO, E. L. R. DE et al. Ferramentas de manutenção preditiva de motores diesel: uma revisão bibliográfica sistemática. Research, Society and Development, v. 9, n. 11, p. e57691110195, 2020.

BAKHTIN, M. Estética da criação verbal. 8. ed. Porto Alegre: UFRGS, 1997.

BARTHOLO, T. L. et al. The use of cognitive instruments for research in early childhood education: constraints and possibilities in the Brazilian context. ProPosições, v. 31, n. 1, p. 220180036, 2020.

BOCASANTA, D. M.; KNIJNIK, G. Escola e sociedade de consumidores: um estudo com crianças "catadoras". Educação em Revista, v. 28, n. 4, p. 195-222, 2012.

BRERETON, P. et al. Lessons from applying the systematic literature review process within the software engineering domain. Journal of Systems and Software, v. 80, n. 4, p. 571-583, 2007.

BURIGO, A. C.; PORTO, M. F. DE S. Trajetórias e aproximações entre a saúde coletiva e a agroecologia. Saúde em Debate, v. 43, n. spe8, p. 248-262, 2019.

CARMO, A. B. DO; CARVALHO, A. M. P. DE. Construindo a linguagem gráfica em uma aula experimental de física. Ciência \& Educação, v. 15, n. 1, p. 61-84, dez. 2009.

CONFORTO, E. C.; AMARAL, D. C.; SILVA, S. L. DA. Roteiro para revisão bibliográfica sistemática: aplicação no desenvolvimento de produtos $\mathrm{e}$ gerenciamento de projetos. $\mathbf{8}^{\circ}$ Congresso Brasileiro de Gestão de Desenvolviemnto de Produto - CNGDP 2011, n. 1998, p. 1-12, 2011.

DE ANDRADE, F. C. et al. Aspects of university students' graph sense in a virtual learning environment. Bolema - Mathematics Education Bulletin, p. 462-479, 1 ago. 2020.

DE SOUZA CHIARI, A. S.; DE CARVALHO BORBA, M.; SOUTO, D. L. P. The activity theory in mathematics interactive digital didatic material. Bolema Mathematics Education Bulletin, v. 33, n. 65, p. 1255-1275, 2019. 
DIAS, V. H. A.; DIAS, P. M. C. Escrevendo o "Livro da Natureza" na linguagem da matemática: A lei de Ampère. Revista Brasileira de Ensino de Fisica, v. 37, n. 4, p. $4601,2015$.

DIONIZIO, F. A. Q. et al. A methodological design for teacher conceptions about students production by using semiotic representation and dimensions of teacher's knowledge. Bolema - Mathematics Education Bulletin, v. 32, n. 61, p. 727-748, 1 ago. 2018.

DOURADO, J. S.; CARVALHO, S. A. DA S.; LEMOS, S. M. A. Development of communication of children aged between one and three years old and their relationship with the family and school environments. Revista CEFAC, v. 17, n. 1, p. 88-99, fev. 2015.

DUARTE, P. C. X. et al. A linguagem no ensino de matemática. Nucleus, v. 10, n. 1, p. 17-29, 2013.

FELIX, E. F.; CARRAZEDO, R.; POSSAN, E. Parametric analysis of carbonation process in reinforced concrete structures through Artificial Neural Networks. Revista ALCONPAT, v. 7, n. 3, p. 302-316, 29 set. 2017.

JELINEK, K. R.; BELLO, S. E. L. The production of the subject with high abilities in mathematics and school inclusion in contemporary education. Pro-Posições, v. 29, n. 3, p. 117-137, set. 2018.

KLUSENER, R. Ler, escrever e compreender a matemática, ao invés de tropeçar nos símbolos. 8. ed. Porto Alegre: UFRGS, 2007.

KNIJNIK, G.; JUNGES, D. D. L. V. A Relação Família-Escola e a Prática do "Dever de Casa" de Matemática: um estudo sobre seus tensionamentos. Bolema, v. 28, n. 49, p. 662-681, 1 ago. 2014.

KRIPKA, R. M. L. et al. Educação em ciências e matemática: a função da linguagem no contexto da sala de aula. Ensaio - Pesquisa em Educação em Ciências (Belo Horizonte), v. 19, n. 0, p. e2657, 18 dez. 2017.

LAMÔNICA, D. A. C. et al. Klinefelter syndrome: a speech-language and neuropsychological assessment. Revista CEFAC, v. 20, n. 5, p. 665-671, out. 2018.

LORENSATTI, E. Linguagem matemática e Língua portuguesa: diálogo necessário na resolução de problemas matemáticos. Conjectura: filosofia e educação, v. 14, n. 2, p. 89-99, 2009.

LUVISON, C. DA C.; GRANDO, R. C. Gêneros textual e a matemática: Uma articulação possível no contexto da sala de aula. Revista Reflexão e Ação, Santa Cruz do Sul, v. 20, n. 2, p. 154-185, 2012.

MADALENA, S. P.; CORREA, J.; SPINILLO, A. G. Mathematical knowledge and language in deaf students: The relationship between the recitation of a numerical 
sequence and Brazilian sign language proficiency. Estudos de Psicologia, v. 37, n. 0 , p. e180175, 2020.

MONTOITO, R. In-between places: A small invented inventory on mathematics and literature. Bolema - Mathematics Education Bulletin, v. 33, n. 64, p. 892915, 2019.

MOREIRA, P. C.; MOREIRA, P. C. Inadequacy of modern Algebraic language use for translating mathematical sentences in Euclid's Elements. Bolema Mathematics Education Bulletin, v. 32, n. 62, p. 907-926, 1 dez. 2018.

OLIVEIRA, M. E. DE. Palavra de Ordem em Aula de Matemática: o erro e a besteira. Bolema, v. 31, n. 58, p. 629-641, set. 2017.

PAVANELLO, R. M.; LOPES, S. E.; ARAUJO, N. S. R. DE. Leitura e interpretação de enunciados de problemas escolares de matemática por alunos do ensino fundamental regular e educação de jovens e adultos (EJA). Educar em Revista, v. Especial, n. 1, p. 125-140, 2011.

PELOSI, M. B.; FERREIRA, K. G.; NASCIMENTO, J. S. Occupational therapy activities developed with children and pre-teens with down syndrome. Brazilian Journal of Occupational Therapy, v. 28, n. 2, p. 511-524, 1 jun. 2020.

PRAIS, J. L. DE S.; ROSA, V. F. DA. Nuvem de palavras e mapa conceitual: estratégias e recursos tecnológicos na prática pedagógica. Nuances: estudos sobre Educação, v. 28, n. 1, p. 201-219, 2017.

REZENDE, F. et al. Qualidade da educação científica na voz dos professores. Ciência \& Educação, v. 17, n. 2, p. 269-288, 2011.

RODRIGUES, S. DA S. Eficácia docente no ensino da matemática. Ensaio, v. 25, n. 94, p. 114-147, 2017.

SCHNEIDER, S. et al. Os efeitos da pandemia da Covid-19 sobre o agronegócio e a alimentação. Estudos Avancados, v. 34, n. 100, p. 167-188, 1 jan. 2020.

SEPÚLVEDA, F.; CALDERÓN, E.; ESPINOZA, M. J. Characterization of pedagogical practice of high school teachers participating on the program of assistance and effective access to higher education. Revista Electronica Educare, v. 23, n. 2, p. 1-24, 2019.

SILVA, W. R.; SILVA, K. L. S.; BORBA, L. DE C. Construção da reflexão na escrita acadêmica por professores em formação inicial. Revista Brasileira de Linguística Aplicada, v. 16, n. 2, p. 277-308, jun. 2016.

TIRADO CARVAJAL, B.; GUALDRÓN PINTO, É.; ÁVILA ZÁRATE, A. Estrategia didáctica para fortalecer la competencia de comunicación matemática por medio de la fotografía. Revista Logos, Ciencia \& Tecnología, v. 12, n. 1, 30 nov. 2019.

VALLILO, S. A. M. O estudo da Linguagem Matemática na sala de aula: uma abordagem através da Resolução de Problemas. Encintro Brasileiro de 
Estudantes de Pós-Graduação em Educação Matemática, p. 10, nov. 2016.

VASCONCELLOS-SILVA, P. R.; SAWADA, A. Análise de conteúdo de nuvens de palavras produzidas na comunidade virtual "hepatite C". V Seminário Internacional de pesquisa e Estudos Qualitativos, p. 1-12, 2018. 